\title{
Static and Dynamic Experimental Analysis of An Immersion Joint
}

\author{
WenhaoXIAO \\ PhD Candidate \\ Ghent University \\ Ghent, Belgium \\ Wenhao.Xiao@Ugent.be
}

\author{
YongYUAN \\ Professor \\ Tongji University \\ Shanghai, China \\ yuany@tongji.edu.cn
}

\author{
LUCTAERWE \\ Professor \\ Ghent University \\ Ghent, Belgium \\ Luc.Taerwe@Ugent.be
}

\author{
HaitaoYU \\ Lecturer \\ Tongji University \\ Shanghai, China \\ yuhaitao@tongji.edu.cn
}

\section{Summary}

As the weakest part of an immersed tunnel, the immersion joint is the key element in research in this field. Relatively large deformations and internal forces may be induced in the immersion joint subjected to various loading types. Based on a real project, the shear mechanical behaviour is investigated by large scale model test. To explore the performance of the immersion joint, compression-shear loads are applied on a tunnel segment in a specific test set-up. For the applied loading schemes, different levels of axial force, corresponding to the water depth of the joint, are considered as well as varying amplitudes of the shear force. Based on these results, both the static and dynamic shear stiffness of an immersion joint were analysed. The results of the test indicate that the static shear stiffness of the joint increases linearly with the axial force and the same trend is found for the dynamic one. Moreover, the dynamic stiffness is larger than the static one.

Keywords: immersed tunnel; immersion joint; shear key; structural experiment; shear stiffness.

\section{Introduction}

An immersion joint is the connecting part between two adjacent elements of an immersed tunnel. Compared to that of the elements, the stiffness of the immersion joint is relatively small. When it is subjected to shear actions, whether resulting from vertical foundation settlement or horizontal earthquake movements, shear-resistance of the joint is the main concern for a safe and reliable water-proof design. Hence, the immersion joint is always considered as a key part not only for the connection between elements but also the proof for the water tightness.

A flexible immersion joint, which normally includes a rubber seal and the shear keys installed between two adjacent elements, has been a common solution in practice for more than 50 years. The way in which the shear keys and the rubber seal behave in the joint together is of importance to a comprehensive understanding of the shear behavior of the joint. The shear behavior of the joint is mainly characterized by its stiffness. However, only few experimental results on the joint under shear loading are available although they are applied in practice for a long time already. So farre search on the shear performance has mainly been conducted by simulation ${ }^{[1-3]}$. The use of a linear or bi-linear model to simulate a shear key in a numerical analysis of a joint under lateral shear actions is based on simplified assumptions.

To figure out the shear performance of an immersion joint under transverse shear action, an experimental investigation on the static and dynamic shear stiffness of a model immersion joint is presented in this paper. Compression-shear quasi-static loading is cyclically applied to a specimen, with a geometric scale of $1 / 10$ with respect to a real design. The patterns of compression-shear are set-up according to a certain axial water pressure on a joint, to which it would be subjected during its service life at typical buried depths, and to transverse shear movement due to seismic actions. The lateral forces are applied cyclically at increasing amplitude in the horizontal plane. Through observed load-deformation curves, both the static and dynamic shear stiffness of the scaled joint are obtained and analysed. 


\section{Background}

\subsection{Immersion Joint}

The immersion joint discussed is based on a real project, the "Hong Kong-Zhuhai-Macao Bridge (HZMB)", which is being under construction. As can be seen in Fig. 1, the tunnel part in it is approximately $5,664 \mathrm{~m}$ in length. It consists of 33 elements and is finally connected to two artificial islands. The length of a typical element is $180 \mathrm{~m}$ and is assembled through 8 segments which are $22.5 \mathrm{~m}$ in length between which are segmental joints. The cross-sectional dimension of the immersion

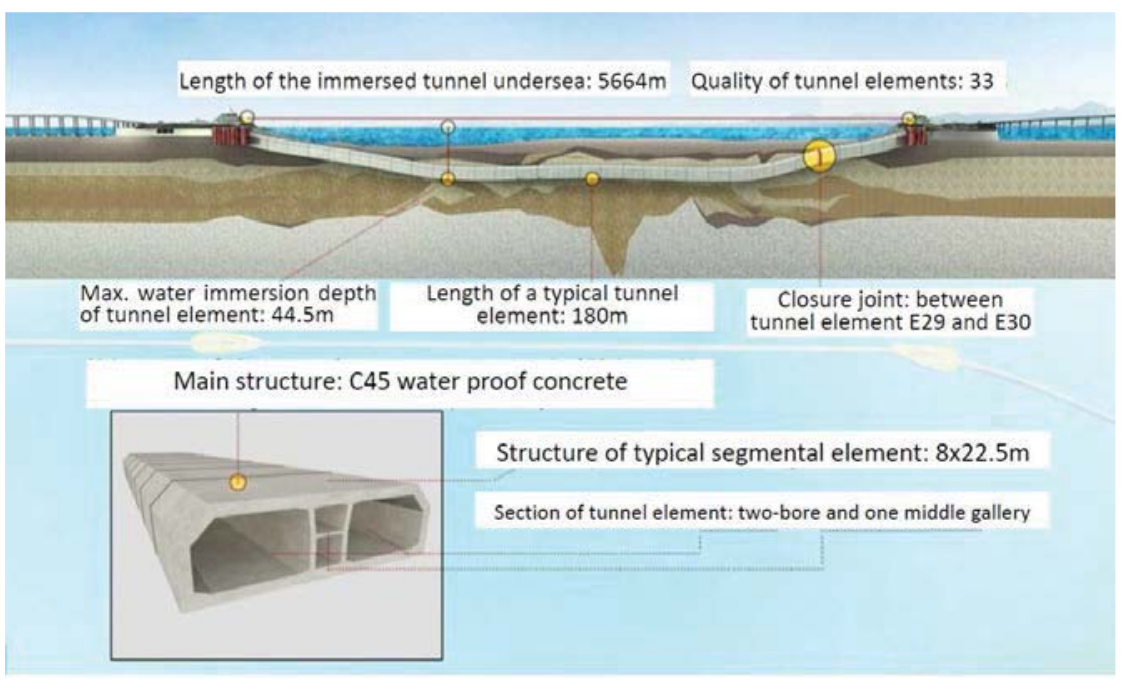

Fig. 1: Information of the immersed tunnelproject ${ }^{[4]}$ joint is about $37.95 \mathrm{~m} \times 11.40 \mathrm{~m}$. The applied immersion joint includes a GINA rubber seal, an Omega water proof, shear keys and steel shell.

When the immersed tunnel is installed, the GINA rubber seal will be highly pressed with a minimum compression, resulting in a waterproof sealing. The initial water pressure varies from the depth of the immersion joint, generating different levels of initial axial force in the joints. Therefore, the purpose of the GINA rubber seal is to seal the immersion joints between two adjacent tunnel elements, ensuring the water-tightness of the structure. If the GINA rubber seal fails, the Omega water proof, regarded as the second water-tightness defence, will start to work to avoid severe leakage.

\subsection{Deformation of immersion joint}

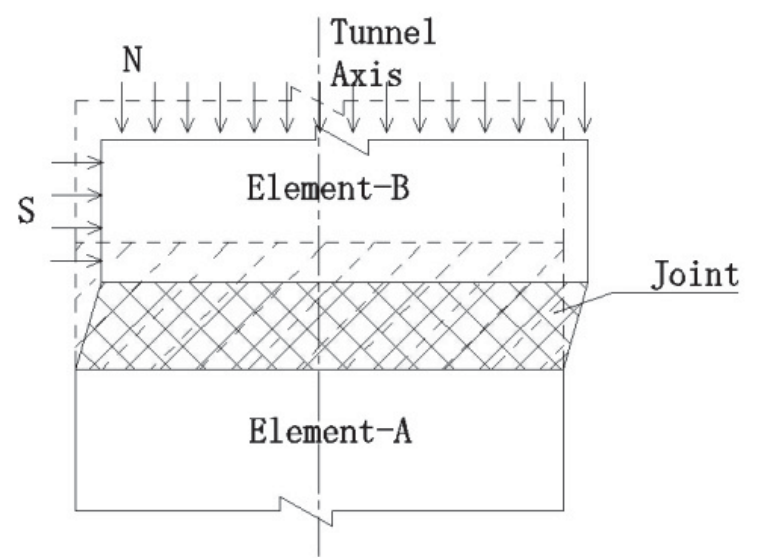

Fig. 2: Deformation of the joint
As a result of earthquake loading and differential settlement, ground motion will cause movement of the immersed tunnel. This movement will result in an extra axial force and a transversal force on the immersion joints ${ }^{[5]}$. Regarding the transversal force, it will be transferred bythe shear keys from one element to another and the rubber seal may also be involved in it due to the parallel system of the rubber seal and the shear keys in transversal direction.

Fig. 2 shows the deformation mode of an immersion joint subjected to both axial force $(\mathrm{N})$ and shear force (S). In this study, the effect of this deformation mode is mainly considered. When the transversal displacement is small, remaining in the elastic stage, both the static and dynamic shear stiffness of the joint can be easily calculated. Then the influencing factors of the stiffness will be analysed as well.

\section{Design of the Experiment}

\subsection{Model tunnel element}

The geometry of a cross section of a model tunnel element is shown in Fig. 3. In this test, two tunnel elements are considered and the dimensions of the elements with a width of $3800 \mathrm{~mm}$, a 


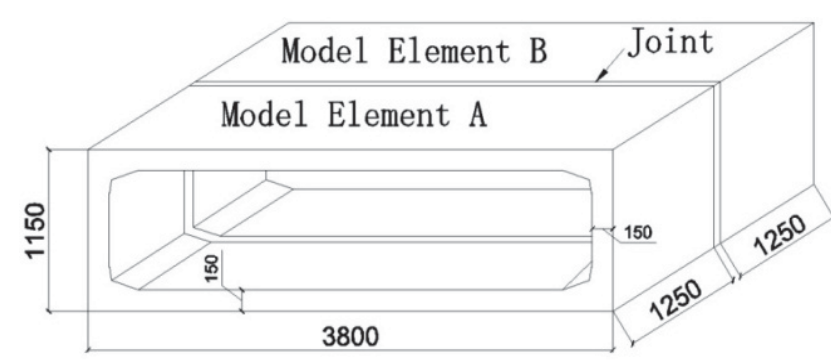

Fig. 3: Model tunnel element

height of $1150 \mathrm{~mm}$, and a length of $1250 \mathrm{~mm}$, are also presented. Referring to the Chinese Code for concrete structure (GB50010-2010) ${ }^{[6]}$, the types of concrete and reinforcement are C50 and HRB335 respectively. Compared to the cross-section of the tunnel element in HZMB, the model one is rectangular and the middle walls are removed due to its small contribution to the effects studied here. Based on the capacity of the available testing facilities and the goal of the experiment, a geometric scale of $1: 10$ is selected. The geometric reinforcement ratio of the model is the same as the original one.

\subsection{Model immersion joint}

The design of the immersion joint also follows the HZMB and the lay-out is also simplified and scaled down according to the experiment. The most concerned components in this test are the GINA rubber seal and the steel shear keys. The steel shell and omega profile are not adopted in this model joint due to the lack of contribution to the experiment.

\subsubsection{Model GINA rubber seal}

A certain type of GINA rubber seal is designed and manufactured independently for this experiment. Fig. 4 displays the dimensions of the model rubber seal and Fig. 5 shows the photo after installation. The scaled rubber seal is $70 \mathrm{~mm}$ wide and $37.5 \mathrm{~mm}$ high. The material parameters and mechanical behaviour can be found in reference ${ }^{[7]}$. It should be noted that normally the GINA rubber seal is considered as a hyper-elastic material.

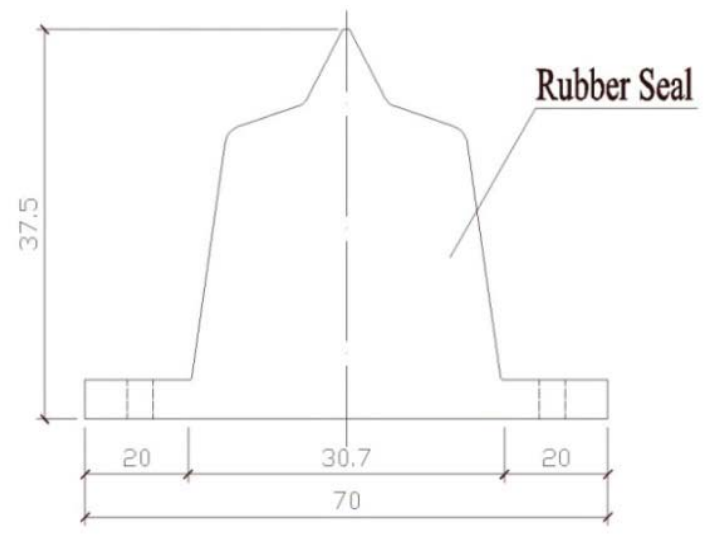

Fig. 4: Dimension of the rubber seal [mm]

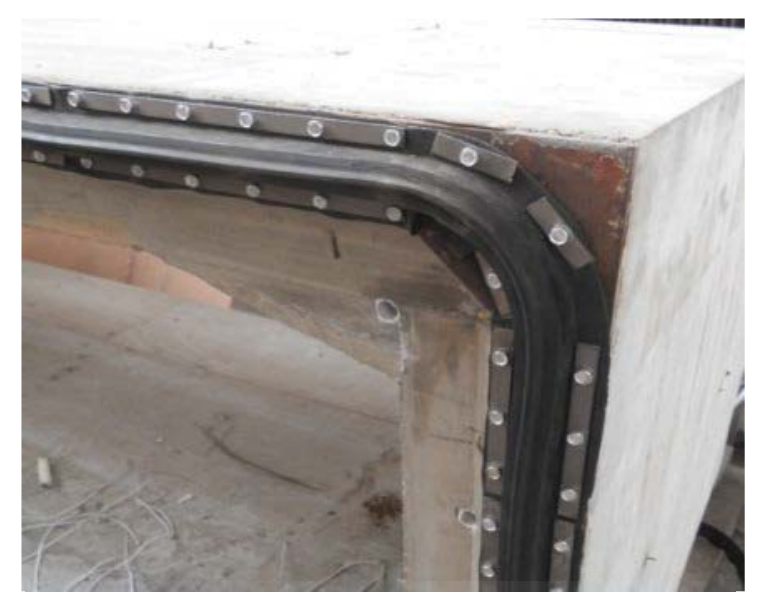

Fig. 5: Installation of the seal

\subsubsection{Model steel shear keys}
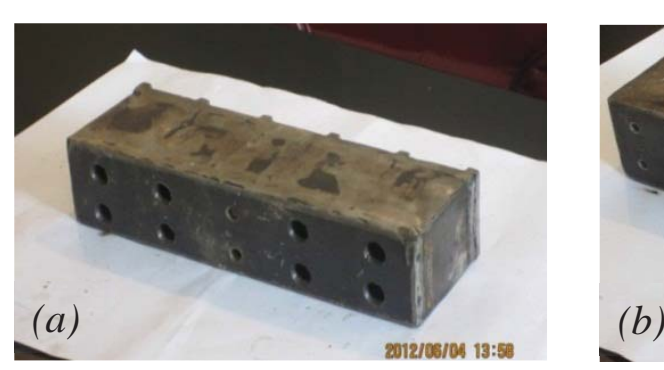

Fig. 6: Photos of the steel shear keys
As the joint is only submitted to horizontal shear, only horizontal shear keys are considered in the test, which are installed in both the roof and bottom slab. Only the stee shear keys are provided. There are two types of horizontal shear keys in the test, HSK1 and HSK2 respectively (Fig. 6 (a) and (b)). They are staggered in different elements and fixed by bolts, which implies that the shear keys can be loaded in two directions (Fig. 7). The main part of each steel shear key is composed by several steel plates, being welded to each other. In 
the top face there are holes for bolts, connecting the shear keys and the embedded components in the tunnel element.

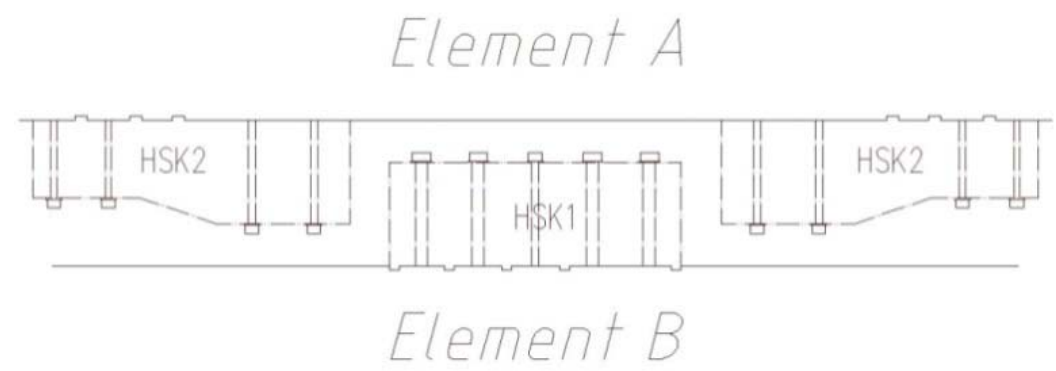

Fig. 7: The staggered shear keys

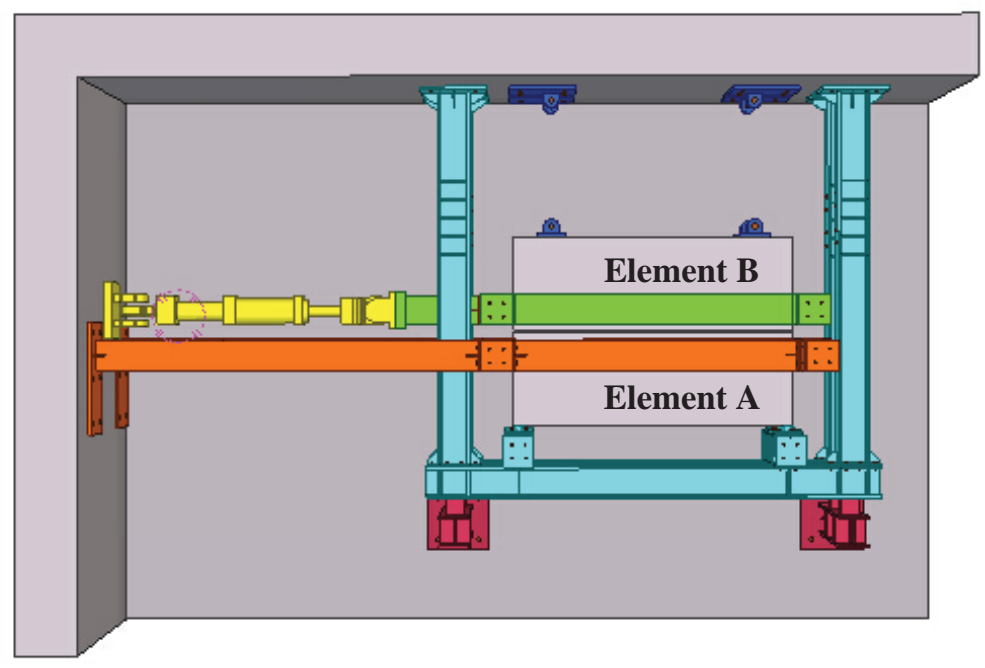

Fig. 8: Plane view of the test set-up

\subsection{Loading Test Set-up}

The tunnel model was placed in a steel loading frameas illustrated in Fig.8.Each part of the frame is shown in different color. During a typical experiment, one tunnel element (Model Element A) is fixed horizontally while the other one (Model Element B) is movable in two directions, resulting in a deformation of the immersion joint. This test set-up, which was designed by our research group, mainly consists of an axial part (light blue) and a transversal part (orange and green) in order to meet the demand of the experiment. The main function of this reaction frame is to provide one model element with 2 degrees of freedom in the horizontal plane while the other element is fixed.

As mentioned, the axial forces are applied to Element B. Fig. 8also shows the 4 loading points (dark blue) for the axial force. Four hydraulic jacks, which only provide pressure but no tension, are situated between this element and the reaction wall. The jacks are controlled synchronically to avoid rotation of Element B. Regarding the shear force, it is applied by the actuator (yellow), which can pull and push the element. Hence the shear force can be cyclic with changing amplitudes.

\subsection{Loading Protocol}

Table 1: Loading cases of the test

\begin{tabular}{cccc}
\hline NO. & Axial Force $[\mathrm{kN}]$ & Shear Amplitude $[\mathrm{kN}]$ & Frequency [Hz] \\
\hline S1 & 0 & \pm 40 & - \\
S2 & 440 & \pm 40 & - \\
S3 & 850 & \pm 40 & - \\
S4 & 1760 & \pm 40 & - \\
D1-X & 0 & \pm 40 & $1,2,3,4.2$ \\
D2-X & 440 & \pm 40 & $1,2,3,4.2$ \\
D3-X & 850 & \pm 40 & $1,2,3,4.2$ \\
D4-X & 1760 & \pm 40 & $1,2,3,4.2$ \\
\hline
\end{tabular}

In the compression-shear test ,the loading pattern is a combination of imposed axial and shear loading. It should be noted that S/D represents Static/Dynamic while $\mathrm{X}$ represents loading frequency of dynamic loadings. Firstly the axial force is applied in order to simulate the initial water pressure. After that, both the static and dynamic shear force is applied respectively while the axial force remains constant. As the immersed tunnel elements

will be located at different water depths, the pressure acting on an immersion joint will vary from 
its location. Therefore, different levels of water depth are considered, corresponding to axial forces of $0 \mathrm{kN}, 440 \mathrm{kN}, 850 \mathrm{kN}$ and $1,760 \mathrm{kN}$ respectively (scaled down according to the model dimensions). For both the static and dynamic shear force, the amplitude of each cycle is $\pm 40 \mathrm{kN}$. Due to the capacity of the actuator, the applied frequency of the dynamic shear force is $1 \mathrm{~Hz}, 2 \mathrm{~Hz}, 3 \mathrm{~Hz}$ and 4.2Hz.Each dynamic case lasts for 8 seconds. A survey of the static and dynamic loading cases is given in Table 1.

\section{Experimental Results and Analysis}

\subsection{Results of static shear test}

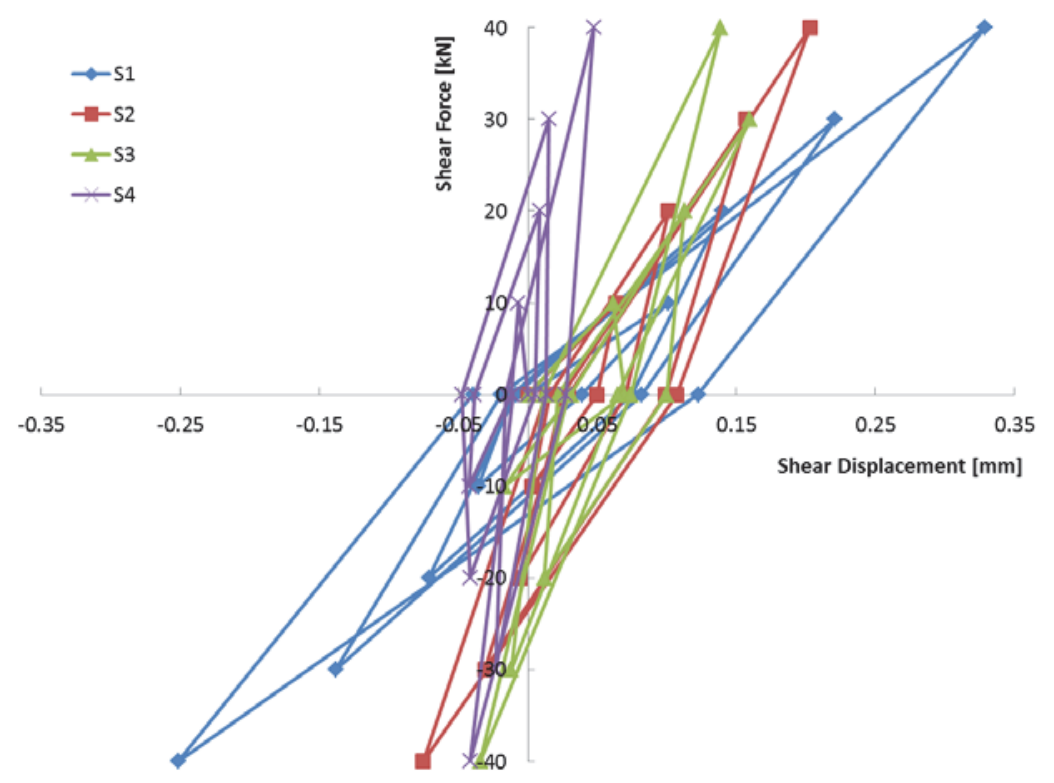

Fig. 9: The force-displacement curves of the joint

Fig. 9 displays the forcedisplacement curves of the static shear tests (S1-S4). Obviously, under the same axial force, the displacement increases with the shear force. The observed shear displacement decreases with increasing axial force when the joint is subjected to the same shear force. In other words, the joint behaves stiffer under larger axial force. The shear displacement under the maximum axial force is 10 times the one without axial force. Although the applied shear force is relative small, a linear behaviour is observed as well as are sidual displacement at unloading. From these curves, the static shear stiffness of the

joint $k_{j}$ can be calculated by equation (1).

$$
k_{j}=\left|\frac{\Delta Q}{\Delta d_{j}}\right|
$$

where $Q$ and $d_{j}$ represents the maximum shear force and the corresponding shear displacement respectively.

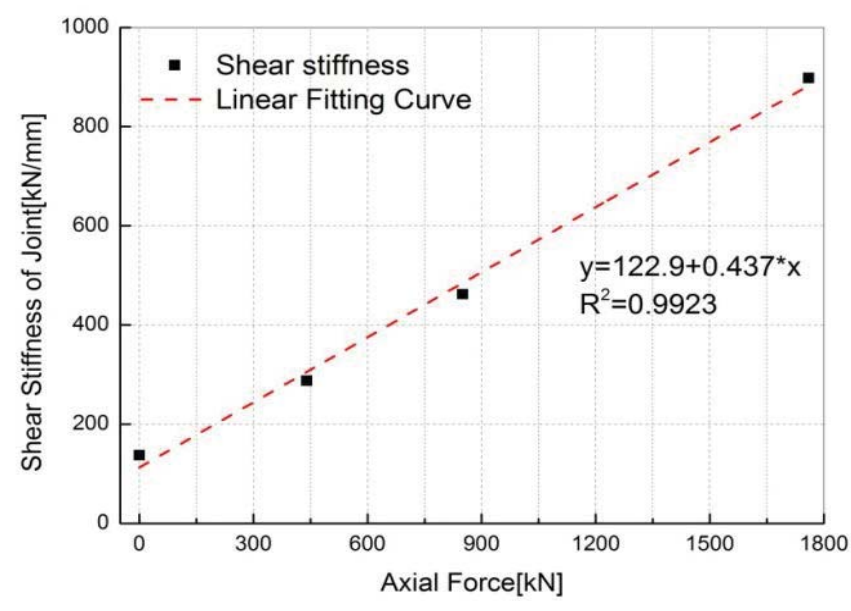

Fig. 10: Static shear stiffness of the joint

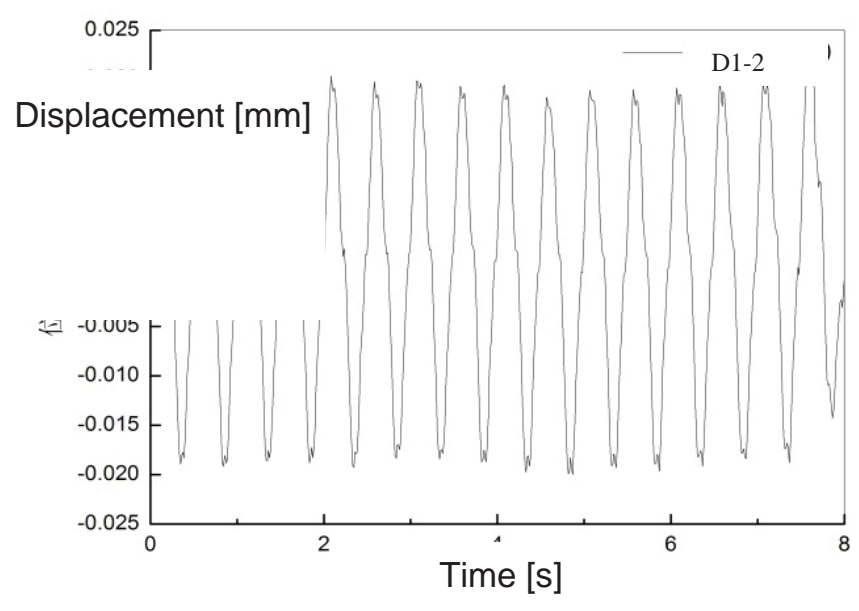

Fig. 11: Recorded data of the dynamic test

The static shear stiffness of the joint is described by a fitted curve.The obtained shear stiffness is shown in Fig. 10 as well as the fitted curve, with a correlation coefficient of 0.99. A linear 
performance of the shear stiffness is observed though a non-linear axial performance was found in previous tests under axial loading only ${ }^{[7]}$. Moreover, the shear stiffness under the maximum axial force is more than six times that without axial force.

\subsection{Results of dynamic shear test}

\subsubsection{Analysis process}

A total of 16 dynamic tests were performed and only the recorded data of one of the mis presented in Fig. 11. The shape of the shear displacement curve almost follows that of the input shear force though slight fluctuations are found in each crest. During the whole test, the joint behaves in a stable way. In each cycle, the slopes of the loading and unloading curve remain constant.

In order to obtain the dynamic stiffness of the joint, the following method is applied. Firstly the data of the first and the last two seconds are cut off to ensure the stability of the used data. Secondly, the first order Fourier equation (2) in the Curve Fitting Tool of Matlab(2011b) is applied to describe the curves.

$$
f(t)=a_{0}+a_{1} \cdot \cos (\varpi t)+\mathrm{b}_{1} \cdot \sin (\varpi t)
$$

where $\mathrm{a}_{0}, \mathrm{a}_{1}, \mathrm{~b}_{1}$ and $\varpi$ are the fitting coefficients.

After the fitting coefficients are determined, the dynamic stiffness of the joint can be calculated by equation (3).

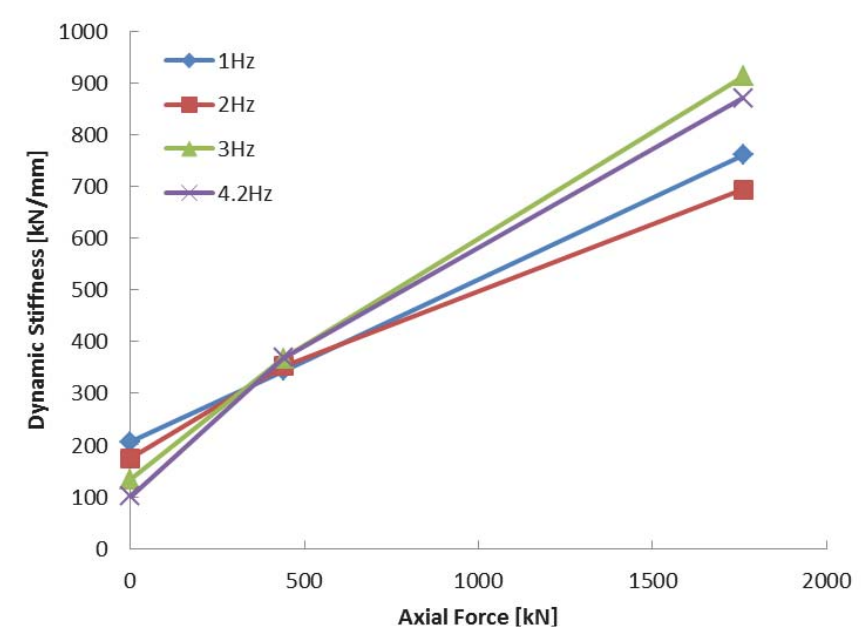

Fig. 12: Influence of the axial force

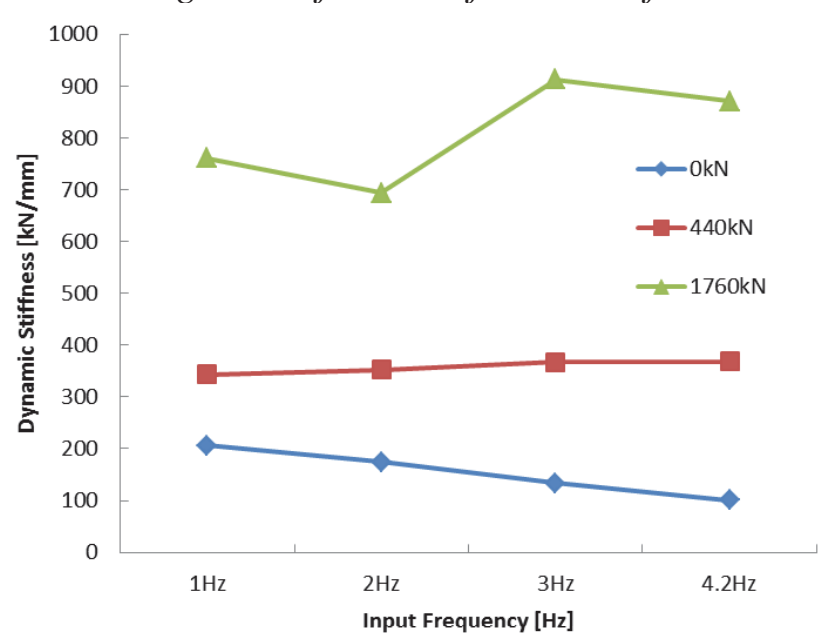

Fig. 13: Influence of the input frequency
$k_{j}^{d}=\frac{Q_{a m p}}{\sqrt{a_{1}^{2}+b_{1}^{2}}}$

where $k_{j}^{d}$ and $Q_{a m p}$ are the dynamic stiffness of the joint and the amplitude of the input shear force respectively. Then the influencing factor can be analysed.

\subsubsection{Influence of the axial force}

Fig. 12 demonstrates the influence of the axial force on the dynamic stiffness of the joint. Apparently, under different values of the input frequency, the dynamic stiffnesses increase with the axial force but the rate of increase depends on the frequency. When the axial force is $0 \mathrm{kN}$, higher frequency leads to smaller stiffness. However, the differences are relatively small. As the axial force increases up to $440 \mathrm{kN}$, the values of the stiffnesses in all cases are very close to each other. When the axial force reaches its peak value, the differences appear again and become larger.

When the joint is highly compressed, the GINA rubber seals become much stiffer, resulting in increasing axial and shear stiffness. This also leads to the remarkable increase of the stiffness of the joint.

\subsubsection{Influence of the input frequency of} the shear force

The influence of the input frequency of the shear force is shown in Fig. 13. Here the 
influence of the axial force is very clear as well. The dynamic stiffness of the joint experiences a decreasing trend with the increase of the input frequency when the axial force is $0 \mathrm{kN}$. As the axial

Table 2: Dynamic stiffness of the joint

\begin{tabular}{cc}
\hline Axial Force $[\mathrm{kN}]$ & Stiffness $[\mathrm{kN} / \mathrm{mm}]$ \\
\hline 0 & 117.3 \\
440 & 367.6 \\
850 & 520.2 \\
1760 & 891.2 \\
\hline
\end{tabular}

obtained through linear interpolation. force increases up to $440 \mathrm{kN}$, a very slightly increasing trend is observed and the differences between the maximum and minimum input frequency are only $6.7 \%$. For the case with the maximum axial force, no obvious trend is found.

The influence of the input frequency is not so sensitive based on the analysis above. The main reason may be that the input frequency is relative low, far away from the frequency domain of the real joint. The dynamic stiffness of the joint subjected to a shear force with a frequency of $4.2 \mathrm{~Hz}$ is listed in Table 2.The value of the axial force of $850 \mathrm{kN}$ is

\subsection{Comparison between static and dynamic results}

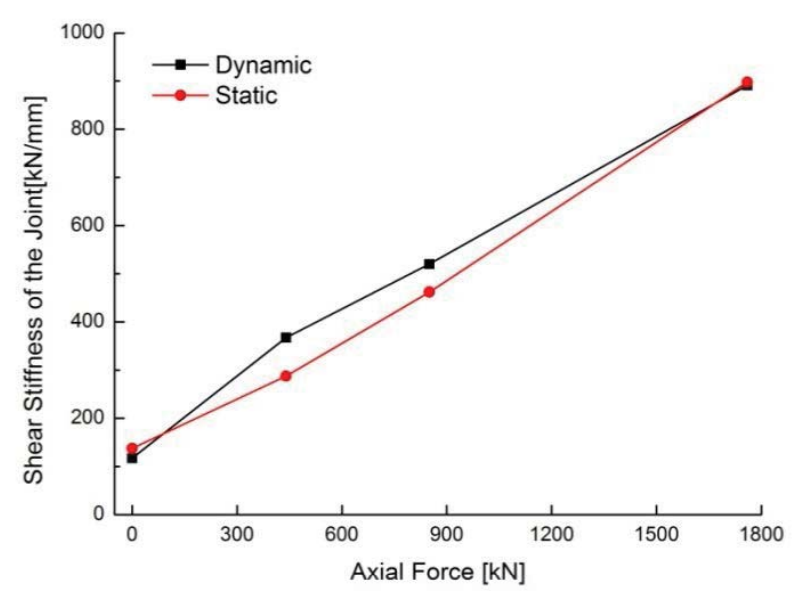

Fig. 14: Comparison between the static and dynamic results

The static and dynamic shear stiffnesses of the joint are compared in Fig. 14. When the axial force is $0 \mathrm{kN}$, the difference between the static and dynamic stiffness is very small $(20 \mathrm{kN} / \mathrm{mm})$. As the axial force increases up to $440 \mathrm{kN}$, the dynamic one increases faster and is 1.28 times the static one. The dynamic one is 1.13 times the static one under the axial force of $850 \mathrm{kN}$. The dynamic and static stiffness are almost the same again under the maximum axial force.

When no axial force is applied in the joint, nearly the complete shear force is transferred to the steel shear keys. Due to the relatively small shear force, the joint, as well as the shear keys, behaves elastically. Moreover, when the joint is highly compressed, the GINA rubber seal become much stiffer, resulting in the same performance of the joint without the axial force. In between, due to the viscosity of the rubber, the behaviour of the joint is influenced by the loading speed though the rubber seal is normally regarded as the hyper-elastic material in practical use.

\section{Conclusions}

The results of static and dynamic shear tests are presented in this paper in order to obtain the shear performance of an immersion joint. Based on the research goal, a certain level of the axial force is applied as well as the static and dynamic cyclic shear loading. Both the static and dynamic shear stiffness of the joint are calculated and analysed. The conclusions are given below.

1. The force-displacement curves of the joint are obtained. Also the static shear stiffness is calculated and a linear behaviour is found.

2. The definition of the dynamic shear stiffness is given and the influencing factorsare analysed. The dynamic stiffness increases with the axial force and is not sensitive to the input frequency of the shear force.

3. The comparison between the static and dynamic shear stiffness of the joint is carried out. The differences tend to be small when the joint is subjected to no axial force and to the maximum axial force. In between, the dynamic one is a bit larger that the static one. 


\section{Acknowledgement}

This work was supported by the National Natural Science Foundation of China [grant number 51208296], [grant number 51478343]; the Shanghai Committee of Science and Technology [grant number13231200503]. The authors acknowledge the support from the Fundamental Research Funds for the Central Universities; Shanghai Educational Development Foundation [grant number 13CG17]; the National Key Technology R\&D Program [grant number 2012BAK24B04].

The authors also acknowledge the supports from the CSC PhD funding and the High-end Foreign Experts Program of Tongji University.

\section{References}

[1] ANASTASOPOUlOSI., GEROLYMOSN., DROSOSV., et al., "Behaviour of Deep Immersed Tunnel Under Combined Normal Fault Rupture Deformation and Subsequent Seismic Shaking”, Bulletin of Earthquake Engineering, Vol. 6, No. 2, 2008, pp. 213-239.

[2] DINGJ., JINX., GUOY., et al., "Numerical Simulation for Large-scale Seismic Response Analysis of Immersed Tunnel”, Engineering Structures, Vol. 28, No. 10, 2006, pp. 13671377.

[3] DING W., LIUP., "Research on the Three Dimensional Nonlinear Stiffness Mechanical Model of Immersed Tube Tunnel Joints", Geo Shanghai: Tunnelling and Underground Constructuon, Shanghai, China, 2014, pp. 1-14.

[4] CCCCHZMB, Tunnel Design Solution [Format: Images], Zhuhai, China, 2011, <http://www.ccchzmb.com/P53-119.biz>.

[5] VAN OORSOUWR., "Behaviour of Segment Joints in Immersed Tunnels under Seismic Loading (Master Thesis)”, Delft University of Technology, Delft, Netherlands, 2008.

[6] Ministry of Housing and Urban-Rural Development of the People's Republic of China, Code for Design of Concrete Stuucture (GB 50010-2010), China Architecture \& Building Press, Beijing, China, 2010.

[7] XIAOW., YUH., YUANY., et al., "Compression-bending behaviour of a Scaled Immersion Joint”, Tunnelling and Underground Space Technology, Vol. 19, 2015, pp. 426-437. 